\title{
Contribution of the North Atlantic subtropical high to regional climate model (RCM) skill in simulating southeastern United States summer precipitation
}

\author{
Laifang $\mathbf{L i} \cdot$ Wenhong $\mathbf{L i} \cdot$ Jiming Jin
}

Received: 25 March 2014 / Accepted: 22 September 2014

(C) Springer-Verlag Berlin Heidelberg 2014

\begin{abstract}
This study assesses the skill of advanced regional climate models (RCMs) in simulating southeastern United States (SE US) summer precipitation and explores the physical mechanisms responsible for the simulation skill at a process level. Analysis of the RCM output for the North American Regional Climate Change Assessment Program indicates that the RCM simulations of summer precipitation show the largest biases and a remarkable spread over the SE US compared to other regions in the contiguous US. The causes of such a spread are investigated by performing simulations using the Weather Research and Forecasting (WRF) model, a next-generation RCM developed by the US National Center for Atmospheric Research. The results show that the simulated biases in SE US summer precipitation are due mainly to the misrepresentation of the modeled North Atlantic subtropical high (NASH) western ridge. In the WRF simulations, the NASH western ridge shifts $7^{\circ}$ northwestward when compared to that in the reanalysis ensemble, leading to a dry bias in the simulated summer precipitation according to the relationship between the NASH western ridge and summer precipitation over the southeast. Experiments utilizing the four dimensional data assimilation technique further suggest that the improved
\end{abstract}

L. Li $\cdot$ W. Li $(\bowtie)$

Earth and Ocean Sciences, Nicholas School of the Environment and Earth Sciences, Duke University, 321C Old Chem. Bldg,

P.O. Box 90227, Durham, NC 27708, USA

e-mail: wenhong.li@duke.edu

J. Jin

Department of Watershed Sciences, Utah State University,

Logan, UT 84322, USA

J. Jin

Department of Plants, Soils and Climate, Utah State University, Logan, UT 84322, USA representation of the circulation patterns (i.e., wind fields) associated with the NASH western ridge substantially reduces the bias in the simulated SE US summer precipitation. Our analysis of circulation dynamics indicates that the NASH western ridge in the WRF simulations is significantly influenced by the simulated planetary boundary layer (PBL) processes over the Gulf of Mexico. Specifically, a decrease (increase) in the simulated PBL height tends to stabilize (destabilize) the lower troposphere over the Gulf of Mexico, and thus inhibits (favors) the onset and/or development of convection. Such changes in tropical convection induce a tropical-extratropical teleconnection pattern, which modulates the circulation along the NASH western ridge in the WRF simulations and contributes to the modeled precipitation biases over the SE US. In conclusion, our study demonstrates that the NASH western ridge is an important factor responsible for the RCM skill in simulating SE US summer precipitation. Furthermore, the improvements in the PBL parameterizations for the Gulf of Mexico might help advance RCM skill in representing the NASH western ridge circulation and summer precipitation over the SE US.

Keywords Southeastern US summer precipitation . North Atlantic subtropical high western ridge $\cdot$ North American Regional Climate Change Assessment Program (NARCCAP) - Weather Research and Forecasting (WRF) model

\section{Introduction}

Summer precipitation significantly influences the southeastern (SE) United States (US) in various aspects, including agriculture, hydrology, and ecology (e.g., Riha et al. 
1996; Manuel 2008; Martinez et al. 2009). In recent decades, water supplies in the area have become increasingly stressed due to the population and economic growth (e.g., Manuel 2008; Seager et al. 2009; Wang et al. 2010). Accurate summer rainfall simulation is thus increasingly important, as it provides a scientific basis for climate prediction and water management for the region.

A common method in regional climate simulation and prediction is the application of regional climate models (RCMs; e.g., Giorgi and Mearns 1999; Leung et al. 2003, 2012; Fu et al. 2005; Mearns et al. 2012). The RCMs show advantages over general circulation models (GCMs) in representing regional climate over various regions, due to their higher horizontal resolution and more sophisticated model physics at regional scales (e.g., Boberg et al. 2010; Rauscher et al. 2010). However, the RCM simulations of SE US summer precipitation show a large spread (e.g. Chen et al. 2003; Liang et al. 2006), limiting their applications in hydrology, water management, and climate change impact assessment (Wood et al. 2004). To date, no comprehensive study at a process level has been undertaken to explore the factors responsible for RCM performance in SE US summer precipitation simulations.

Multiple factors and processes contribute to SE US summer precipitation (e.g., Konrad 1997; Mearns et al. 2003; Kunkel et al. 2012; Li et al. 2013a). For example, summer rainfall is often generated from mesoscale convection cells (e.g., Baigorria et al. 2007), landfalling hurricanes (e.g., Hart and Evans 2001; Knight and Davis 2007; Kunkel et al. 2010), passages of fronts (e.g., Kunkel et al. 2012), and planetary-scale circulation systems (e.g., Henderson and Vega 1996; Li et al. 2011, 2012a). Furthermore, both local and remote climate factors, such as soil moisture and sea surface temperatures (SSTs), can regulate SE US summer precipitation by modulating the abovementioned rainfall generation systems (e.g., Anchukaitis et al. 2006; Wu et al. 2007; Wang et al. 2008, 2010; Xue et al. 2012; Li et al. 2012a).

Among those factors and processes affecting SE US summer precipitation, a planetary-scale atmospheric circulation system, the North Atlantic subtropical high (NASH), has been found to play a significant role at seasonal scales (e.g., Henderson and Vega 1996; Li et al. 2013a). The NASH is a semipermanent high-pressure system in the lower troposphere over the North Atlantic (Davis et al. 1997; Li et al. 2012b). During summer, the NASH intensifies and expands, and its western ridge extends over the east coast of the US. The circulation along its western ridge transports moisture into the SE US, sustaining regional precipitation (Henderson and Vega 1996; Davis et al. 1997; Li et al. 2011, 2012a). Previous observational studies have established a relationship between the NASH western ridge and SE US summer precipitation (Li et al. 2012a, 2013b; Carter et al. 2013), that is, when the NASH western ridge moves southwestward, intensified southerly winds enhance moisture convergence over the SE US, thus favoring heavy precipitation. In contrast, when the ridge extends northwestward over the continental US, moisture is usually transported away from the SE US and sinking motions associated with the NASH dominate the region, which results in a dry summer (Li et al. 2012a, 2013b; Carter et al. 2013). Such a "NASH western ridge-SE US summer precipitation" relationship provides the first-order dynamic control of SE US summer precipitation at the seasonal scale (Li et al. 2012a; Carter et al. 2013; Wuebbles et al. 2014).

Previous research has demonstrated that the skill of GCMs in simulating SE US summer precipitation is determined largely by the models' ability to represent the NASH western ridge (Li et al. 2013b; Wuebbles et al. 2014). The RCMs differ from GCMs in various aspects, such as horizontal resolution, lateral boundary conditions, and physical parameterizations (e.g., Castro et al. 2005; Rummukainen 2010; Feser et al. 2011). It remains unclear whether and how the representation of the NASH western ridge in RCMs impacts their skill in simulating SE US summer precipitation.

This study aims to elucidate the role of the NASH western ridge in RCM simulations of SE US summer precipitation by analyzing the output of the RCMs participating in the North American Regional Climate Change Assessment Program (NARCCAP) and performing simulations with the Weather Research and Forecasting (WRF) model. The specific objectives in this study are: (1) to evaluate RCM simulations for SE US summer rainfall and understand the role of the NASH in such simulations; and (2) to explore the factors and processes that are responsible for the representation of the NASH circulation in RCMs.

The remainder of the manuscript is organized as follows: In Sect. 2, data and the configuration of the WRF model are described. In Sect. 3, the summer precipitation simulated by the NARCCAP RCMs is evaluated. The contribution of the NASH western ridge to RCM-simulated precipitation is further explored by performing WRF simulations, and is described in Sect. 4. In this section, the four dimensional data assimilation (FDDA) experiment is employed to verify the importance of the NASH western ridge to simulating SE US summer precipitation. The possible factors and processes responsible for the representation of the NASH western ridge in RCMs are discussed in Sect. 5. Concluding remarks are included in Sect. 6.

\section{Data and model}

2.1 Observed precipitation and atmospheric circulation from multiple reanalysis datasets

In this study, the observed precipitation data were obtained from the National Oceanic and Atmospheric Administration 
Table 1 Reanalysis datasets used in this study

\begin{tabular}{llll}
\hline Datasets & Temporal coverage; resolution & Horizontal resolution & References \\
\hline NCEP/NCAR & 1948-present; 6-h & $2.5^{\circ} \times 2.5^{\circ}$ & Kalnay et al. (1996) \\
ERA-40 & $1958-2002 ; 6-h$ & $2.5^{\circ} \times 2.5^{\circ}$ & Uppala et al. (2005) \\
NCEP-R2 & 1979-present; 6-h & $2.5^{\circ} \times 2.5^{\circ}$ & Kanamitsu et al. (2002) \\
JRA-25 & 1979 -present; 6-h & T106 & Onogi et al. (2007) \\
NARR & 1979-present; 3-h & $32-\mathrm{km}$ & Mesinger et al. (2006) \\
ERI & 1979-present; 6-h & T255 & Dee et al. (2011) \\
CFSR & 1979-present; 6-h & $0.5^{\circ} \times 0.5^{\circ}$ & Saha et al. (2010) \\
\hline
\end{tabular}

(NOAA) Climate Prediction Center (CPC) unified daily precipitation archive (Higgins et al. 2000). The spatial resolution of the CPC data is $0.25^{\circ}$, approximately $25 \mathrm{~km}$ in the study region. The $\mathrm{CPC}$ data were used to evaluate the performance of the NARCCAP RCMs and WRF in simulating summer precipitation over the SE US, which covers the terrestrial domain over $91^{\circ} \mathrm{W}-76^{\circ} \mathrm{W}, 25^{\circ} \mathrm{N}-36.5^{\circ} \mathrm{N}$ and includes 7 states: Tennessee, Mississippi, Alabama, Georgia, Florida, and North and South Carolina. The summer season is defined as June, July, and August (JJA); the seasonal mean thus refers to daily precipitation averaged over JJA.

The large-scale circulation fields, including the $850 \mathrm{hPa}$ geopotential height and horizontal wind, were analyzed from the perspective of atmospheric dynamics. This study used multiple available reanalysis datasets (Table 1) to derive these variables in order to reduce the potential uncertainties introduced by the choice of reanalysis datasets, and thus ensure the robustness of the analysis results. A reanalysis ensemble method was applied, and the ensemble circulation fields were treated as an approximation of observed atmospheric circulation (Li et al. 2013b; Zhang et al. 2014). These variables simulated by the WRF were compared with the reanalysis ensemble to understand the causes of the precipitation bias in the WRF simulation. The NASH western ridge was defined using $850 \mathrm{hPa}$ geopotential height and zonal wind, following previous studies ( $\mathrm{Li}$ et al. 2011, 2012a). The NASH western ridge is located where tropical easterlies reverse to midlatitude westerlies, and thus the distribution of zonal wind $(u)$ mathematically fulfills $u=0 ; \frac{\partial u}{\partial y}>0$ (Liu and Wu 2004). The intersecting point of the $850 \mathrm{hPa}$ geopotential height $1,560 \mathrm{~m}$ isoline with the identified ridge line was calculated to quantify the location of the NASH western ridge (Li et al. 2011, 2012a).

\subsection{NARCCAP datasets}

SE US summer precipitation and the NASH western ridge circulation simulated by the six RCMs participating in the NARCCAP (Mearns et al. 2009) were analyzed. We focused on the simulations driven by lateral boundary conditions from the National Centers for Environmental Prediction (NCEP)-Department of Energy (DOE) Reanalysis 2 (NCEP-R2, Kanamitsu et al. 2002). The six RCMs are: the Canadian Regional Climate Model version 4 (CRCM), the Experimental Climate Prediction Center's Regional Spectral Model (ECP), the Hadley Centre Regional Model version 3 (HRM3), the fifth-generation Pennsylvania State University-NCAR Mesoscale Model (MM5), the Regional Climate Model version 3 (RCM3), and the Weather Research and Forecasting (WRF) Model. The models' domain covers the entire CONtiguous United States (CONUS) and Canada, and the horizontal resolution is $50 \mathrm{~km}$ (Mearns et al. 2009, 2012).

\subsection{WRF model and experiment design}

The WRF model version 3.3 (Skamarock and Klemp 2008) was used in this study. The WRF is a non-hydrostatic, terrain-following eta-coordinate mesoscale modeling system that has been widely used for regional weather and climate forecasting and research. The experiment domain was configured over the CONUS, with a $36-\mathrm{km}$ horizontal resolution. The domain boundary was set over the flat topography and ocean oceans in order to avoid the possible computational instability introduced by the steep terrain (Fig. 1). Such a CONUS domain configuration is commonly used in RCM simulations of US climate (e.g. Lo et al. 2008; Bowden et al. 2013). The lateral boundary was composed of a 1-point specified zone and a 4-point relaxation zone to smooth potential pseudo-disturbances caused by numerical calculation. The horizontal coordinates used the Lambert conformal conic projection with the standard parallels at $30^{\circ} \mathrm{N}$ and $60^{\circ} \mathrm{N}$. The model consisted of 38 vertical layers, and the top level was set to $50 \mathrm{hPa}$.

The physical parameterization schemes used in this study were the Dudhia shortwave radiation (Dudhia 1989), Rapid Radiative Transfer Model (RRTM) longwave radiation (Mlawer et al. 1997), Thompson microphysics (Thompson et al. 2008), Yonsei Universtiy (YSU) planetary boundary layer physics (Noh et al. 2003), and Noah land surface model (Chen and Dudhia 2001). Four 


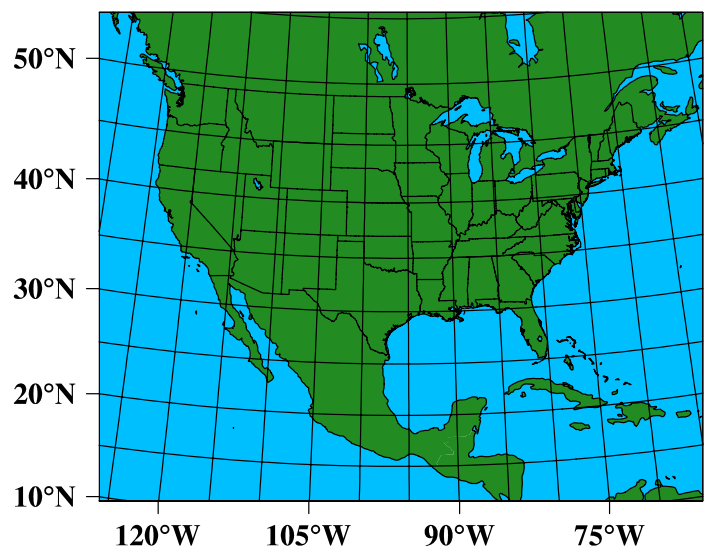

Fig. 1 Domain for WRF experiment

different cumulus schemes were compared in this study, because the cumulus schemes are likely to introduce large uncertainties to the simulations of SE US summer precipitation (e.g., Jankov et al. 2005; Bukovsky and Karoly 2009; Li et al. 2014). The four cumulus schemes are the Kain-Fritsch (K-F; Kain 2004), Betts-Miller-Janjic (BMJ; Janjic 1994; 2000), Grell-3 (Grell and Dévényi 2002), and Zhang-McFarlane (Zhang and McFarlane 1995) schemes, respectively.

NCEP-R2 (Kanamitsu et al. 2002) was adopted to provide initial and boundary conditions for the simulations. In our analysis, simulations driven by NCEP-R2 data were compared with those driven by European Centre for Medium-Range Weather Forecasts (ECMWF) Reanalysis (ERA)-Interim data (Dee et al. 2011). We found that the choice of driving reanalysis did not influence the summer rainfall simulation results in a discernible way (figures not shown).

The summer of 2001 was selected as our simulation period, according to a pattern recognition algorithm that

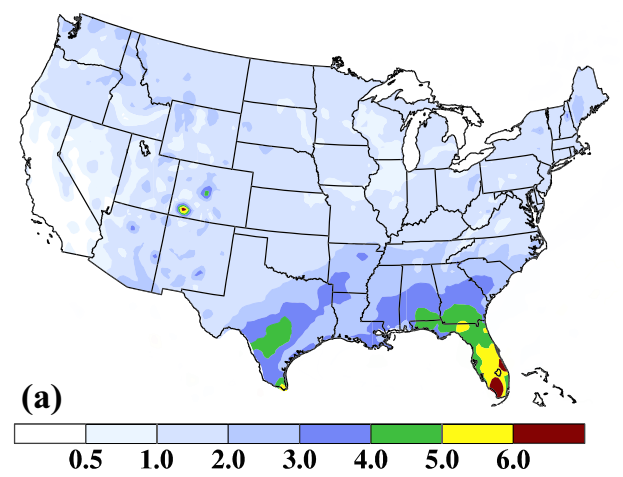

Fig. 2 a The spread of RCM-simulated US summer (JJA) precipitation climatology (1980-2004) among the six NARCCAP RCMs driven by NCEP-2 reanalysis (shaded, unit: $\mathrm{mm}^{\text {day }}{ }^{-1}$ ); $\mathbf{b}$ bias (bars, unit: $\mathrm{mm} \mathrm{day}^{-1}$ ) in SE US areal-averaged precipitation in each of the synthesizes three score metrics to identify a summer precipitation case representative of the rainfall climatology over the SE US ("Appendix"). The WRF simulation was initialized on May 1, 2001, and run through August 31, 2001. The first month was discarded as spin-up.

\section{Performance of NARCCAP RCMs in simulating SE US summer precipitation}

The skills of current RCMs in simulating SE US summer precipitation were evaluated by analyzing the output of all six RCMs participating in the NARCCAP. Figure 2a shows the spread of simulated summer precipitation climatology (1980-2004) among the six RCMs over the CONUS domain. Here, the spread refers to the difference between the highest and lowest precipitation rate among the six RCMs. A larger difference indicates a higher uncertainty in the skill of the RCM in simulating the summer precipitation.

Summer precipitation simulated by the NARCCAP RCMs shows a larger spread over the SE US compared to other regions (Fig. 2a). The uncertainty exceeds $3 \mathrm{~mm} \mathrm{day}^{-1}$ (about $80 \%$ of SE US rainfall climatology) for more than $60 \%$ of the grid cells in the southeast, about $2 \mathrm{~mm}$ day $^{-1}$ higher than that over the Northeast and the Pacific Northwest (Fig. 2a).

The large spread in the RCM-simulated precipitation over the SE US is also reflected in the domain-averaged summer precipitation. Among the six RCMs, four models (CRCM, ECP, MM5, and RCM3) produce wet biases, while the other two generate dry biases (HRM3 and WRF; Fig. 2b). Both the dry and wet biases exceed one standard deviation of the observed summer precipitation over the SE US and are statistically significant at the $\alpha=0.01$ level (student $t$ test).

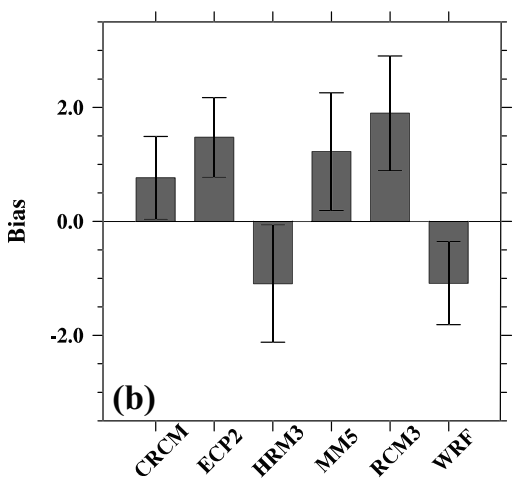

6 RCMs. The error bar represents the upper and lower bound of the bias as defined by one standard deviation of the interannual variation of precipitation 
Fig. 3 1980-2004 JJA climatology of $850 \mathrm{hPa}$ geopotential height (blue contours, unit: $\mathrm{gpm}$ ) and $\mathrm{u}=0$ isoline (red contours) in: a Reanalysis ensemble; and $\mathbf{b}$ WRF and $\mathbf{c}$ MM5 simulations in NARCCAP. The NASH western ridge is defined as the intersecting points between the 1560 -geopotential height isolines (bold contours) and the $\mathrm{u}=0$ isolines
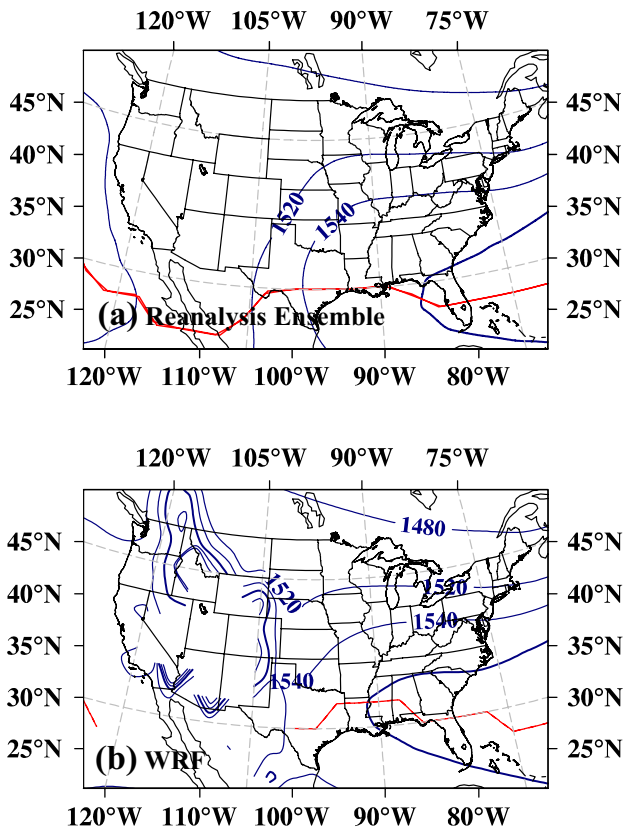

The large spread and large bias in the NARCCAP RCMsimulated SE US summer precipitation are consistent with individual RCM studies including Chen et al. (2003), Liang et al. (2006) and Mearns et al. (2012). The RCM-simulated biases in SE US summer precipitation may be caused by errors in the NASH western ridge pattern, according to the analysis of large-scale circulation simulated by the WRF and MM5. These two models are among the three that provide the variables required to determine the location of the NASH western ridge. Furthermore, these two models do not use the spectral nudging technique (Mearns et al. 2012), and thus reflects the real ability of RCMs to simulate the largescale circulation and precipitation. The WRF-simulated $\mathrm{NASH}$ western ridge is located at $92^{\circ} \mathrm{W}, 32^{\circ} \mathrm{N}$ (Fig. $3 \mathrm{~b}$ ), about $8^{\circ}$ northwest of the location of the NASH ridge in the reanalysis ensemble (Fig. 3a). The erroneous northwestward location of the NASH western ridge results in an artificial anticyclone over the SE US (not shown here). Previous observational studies demonstrate that the presence of the anticyclone will reduce nonlocal moisture supplies for the SE US ( $\mathrm{Li}$ et al. 2013a), inhibit the onset of precipitation (Li et al. 2012a), and causes the dry bias (Fig. 2b). The concurrence of the precipitation dry bias with the erroneously northwestward positioning of the NASH western ridge is consistent with the observed relationship between the NASH western ridge and SE US summer precipitation. In contrast, the NASH western ridge is located at $87^{\circ} \mathrm{W}$, $26^{\circ} \mathrm{N}$ as simulated by the MM5 (Fig. 3c), which is about $1^{\circ}$ southwest of that from the reanalysis ensemble (Fig. 3a). The relatively southwestward position of the NASH western ridge in the MM5 can explain the wet bias in SE US summer precipitation, to some extent (Fig. 2b).
The above analysis of WRF and MM5 simulated NASH western ridge circulation suggests that the SE US summer precipitation bias in these two RCMs can be explained by the "NASH western ridge-SE US summer precipitation" relationship ( $\mathrm{Li}$ et al. 2012a). A previous study has attributed the skill of GCMs in simulating SE US summer precipitation to their ability to represent the NASH western ridge dynamics (Li et al. 2013a). This study further suggests that the NASH circulation could also be responsible for the skill of RCMs in simulating SE US summer precipitation, although the working mechanisms of RCMs and GCMs differ in various aspects, such as boundary conditions, horizontal resolution, and model physics (Castro et al. 2005).

\section{Dynamic contributions of the NASH western ridge to RCM biases in SE US summer precipitation: WRF simulations}

Generally, factors contributing to rainfall simulations fall into two categories: large-scale circulation patterns and subgrid-scale parameterizations (e.g. Arakawa 2004). On one hand, large-scale circulation associated with the NASH controls SE US summer precipitation primarily at a seasonal scale (e.g., Li et al. 2012a, 2013a; Carter et al. 2013; Wuebbles et al. 2014). Furthermore, the ability to represent the NASH western ridge contributes to the skill of GCMs in simulating SE US summer precipitation (Li et al. 2013b). On the other hand, summer rainfall simulations over the SE US are also sensitive to the choice of physical parameterization schemes, especially the cumulus scheme 

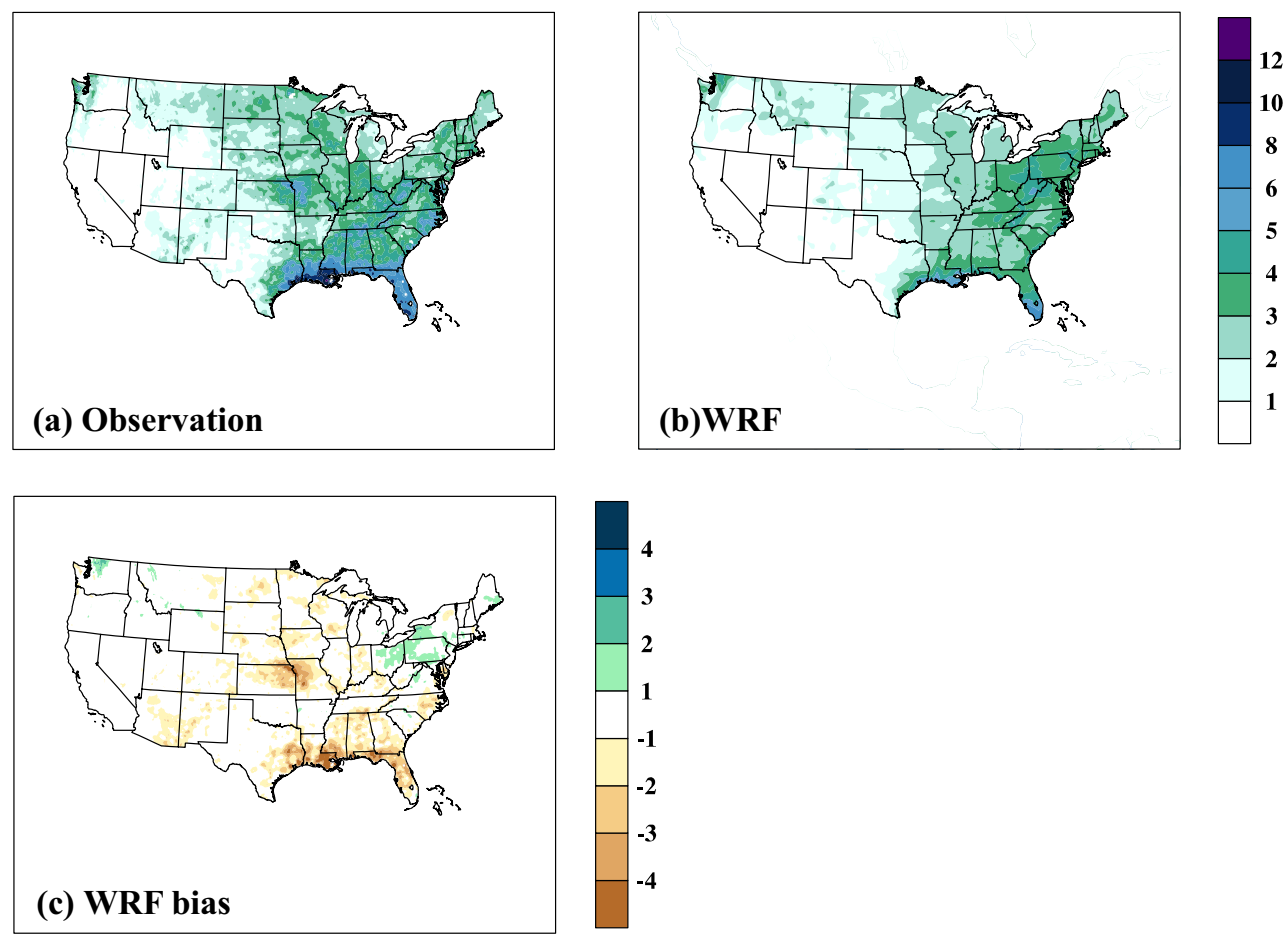

Fig. 42001 US summer (JJA) precipitation (shaded, unit: $\mathrm{mm} \mathrm{day}^{-1}$ ): a observations; b WRF; $\mathbf{c}$ bias of summer precipitation (shaded, unit: $\mathrm{mm} \mathrm{day}{ }^{-1}$ ) in WRF simulations

(e.g. Jankov et al. 2005; Bukovsky and Karoly 2009; Li et al. 2014). In this study, we further assessed these two categories of factors in SE US summer precipitation simulations using the WRF model. Specifically, we analyzed the simulated NASH western ridge circulation and performed sensitivity experiments with different cumulus schemes.

\subsection{SE US dry bias and the northwestward movement of the NASH western ridge in WRF}

Figure 4 shows the simulated summer precipitation in 2001 by WRF and its comparison with observations. The precipitation simulated with the four different cumulus schemes in WRF is ensembled so that the uncertainties due to cumulus scheme are minimized (Boberg et al. 2010). Figure 4 indicates that the WRF model reasonably captures the spatial pattern of summer rainfall over the SE US (Fig. 4a, b), with a high pattern correlation coefficient $(0.60)$ with observations. Specifically, the summer precipitation shows a southeast-northwest oriented gradient across the SE US, with the highest precipitation rate occurring over the coastal regions. However, the WRF model substantially underestimates the intensity of summer precipitation in the region. On average, the WRF simulations result in a net dry bias of $1.3 \mathrm{~mm} \mathrm{day}{ }^{-1}$ over the terrestrial areas within the SE US domain $\left(25^{\circ} \mathrm{N}-36.5^{\circ} \mathrm{N}, 91^{\circ} \mathrm{W}-76^{\circ} \mathrm{W}\right)$. The dry bias is more apparent over the coastal regions (more than $3 \mathrm{~mm} \mathrm{day}^{-1}$ ), consistent with the WRF simulations in the NARCCAP (Mearns et al. 2012).

Figure 5 compares the simulated precipitation using different cumulus schemes in WRF, with the other parameterization schemes remaining the same as described in Sect. 2.3. The dry bias exists over the SE US among these four schemes (Fig. 5e-h), although the spatial distributions of precipitation differ slightly (Fig. 5). Averaged over the region, the net biases range from $-0.92 \mathrm{~mm} \mathrm{day}^{-1}$ (K-F scheme; Fig. 5e) to $-1.52 \mathrm{~mm} \mathrm{day}^{-1}$ (Zhang-McFarlane scheme; Fig. 5h), and all are statistically significant at the $\alpha=0.01$ level (student $t$ test). Such a dry bias has also been noticed in previous WRF modeling studies, where different cumulus parameterization schemes have been implemented (e.g. Mearns et al. 2012; Sobolowski and Pavelsky 2012; Bowden et al. 2013). Thus, the WRF-simulated SE US dry biases (Figs. 4, 5) may not be caused only by the choice of cumulus scheme.

By contrast, errors in the NASH western ridge circulation largely account for the bias. Consistent with the "NASH western ridge-SE US summer precipitation" relationship in observations, GCM simulations, and NARCCAP RCM simulations (Fig. 3; Li et al. 2011, 2012a; Carter et al. 2013; Wuebbles et al. 2014), the WRF dry bias in SE US summer precipitation also concurs with an erroneous northwestward position of the NASH western ridge. The ensemble of reanalysis datasets indicates that the 


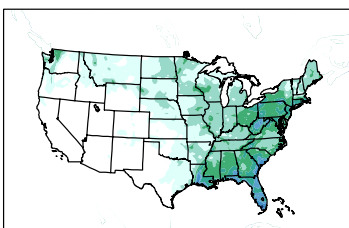

(a) K-F

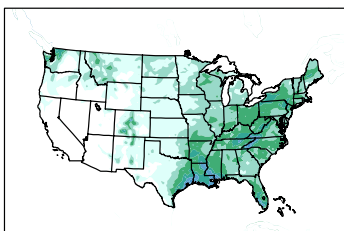

(b) BMJ

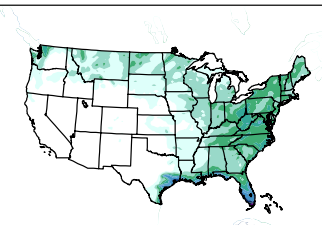

(c) Grell-3

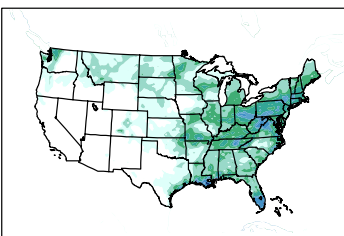

(d) Zhang-McFarlane

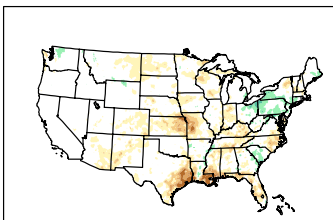

(e) $\mathrm{K}-\mathrm{F}$

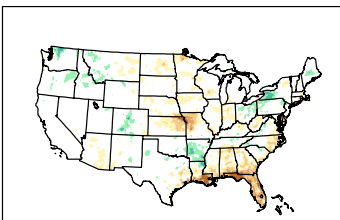

(f) BMJ

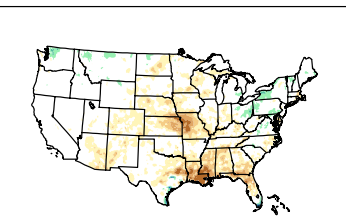

(g) Grell-3

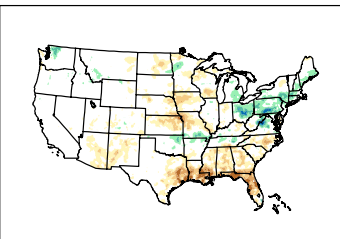

(h) Zhang-McFarlane

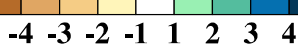

Fig. 52001 US summer (JJA) precipitation ( $\left(\right.$ haded, unit: $\mathrm{mm} \mathrm{day}^{-1}$ ) as simulated by WRF with different cumulus schemes: a $K$ - $F$; b $B M J$; c Grell-3; and $\mathbf{d}$ Zhang-McFarlane; $\mathbf{e}-\mathbf{h}$ show the precipitation bias simulated by each cumulus scheme compared with observations

NASH western ridge is located over the Gulf of Mexico, about $87^{\circ} \mathrm{W}$ and $27^{\circ} \mathrm{N}$ (Fig. 6a) in 2001. Compared to the reanalysis ensemble (Fig. 6a), the modeled western ridge extends northwestward by more than $7^{\circ}$ into Texas (around $93^{\circ} \mathrm{W}$ and $31^{\circ} \mathrm{N}$, Fig. $6 \mathrm{~b}$ ). The ridge locations simulated by each individual cumulus scheme differ to some extent. However, almost all of them are located northwest of the reanalysis ensemble, outside the uncertainty range defined by the seven reanalysis datasets (Fig. 6c). The multivariatepaired Hotelling's t-square test ${ }^{1}$ (Hotelling 1931) suggests that the erroneous northwestward extension of the NASH western ridge in the WRF simulation is statistically significant at the $\alpha=0.0001$ level.

Corresponding to the biased northwestward location of the NASH western ridge, anticyclonic circulation along the ridge extends farther over the continental US (Fig. 6b). Consequently, the simulated southerly wind over the SE US weakens due to the erroneous northerly wind in the eastern portion of the anticyclone (Fig. 6b). The weakened southerly wind transports less moisture from the tropical oceans into the SE US, resulting in the dry bias in the simulated summer rainfall ( $\mathrm{Li}$ et al. 2013a).

\footnotetext{
1 The null hypothesis for the Hotelling's $t$ square test is that the WRF-simulated NASH western ridge does not differ significantly from that in reanalysis datasets. According to the test, the null hypothesis can be rejected with a $99.99 \%$ confidence level, suggesting that the erroneous northwestward extension of the ridge is significant.
}

\subsection{Correction in the NASH western ridge circulation and its contribution to the reduced bias in SE US summer precipitation}

The WRF simulations of the 2001 summer climate over the CONUS indicates that the precipitation biases over the SE US are most likely caused by the inaccurately simulated circulation along the NASH western ridge. Thus, an improved simulation of large-scale circulation (especially the NASH western ridge) could potentially reduce the RCM bias in SE US summer precipitation.

To verify this, we performed experiments utilizing the FDDA. The FDDA is an interior grid-nudging technique that continuously nudges the modeled thermodynamic and dynamic variables toward the driving reanalysis during the simulations (Stauffer and Seaman 1990). Previous studies have applied FDDA to improve climate downscaling skills over the US (e.g., Lo et al. 2008; Otte et al. 2012; Bowden et al. 2013). In this study, however, the application of FDDA was for the purpose of identifying the potential sources of RCM skill in simulating SE US summer precipitation. Specifically, two sets of FDDA experiments were designed: thermodynamic and dynamic FDDA. In the thermodynamic FDDA experiment, temperature and specific humidity were nudged toward NCEP-R2 at 6-h intervals during the simulation, while the wind fields were generated by WRF. In contrast, in the dynamic FDDA experiment, the WRF-simulated three-dimensional wind fields were nudged while temperature and specific humidity were not. Thus, the improvement in the simulated precipitation 
Fig. 62001 JJA $850 \mathrm{hPa}$ geopotential height (contour, unit: gpm) and wind (vector, unit: $\mathrm{m} \mathrm{s}^{-1}$ ) in a the ensemble of seven reanalysis datasets, and $\mathbf{b}$ the WRF simulation. The contour interval is 20 gpm, and the bold curves are 1,560-gpm isolines. The bias of v-wind in WRF simulations is shaded (unit: $\mathrm{m} \mathrm{s}^{-1}$ ). The location of the NASH western ridge in 2001 summer as calculated from each of the seven reanalysis datasets (upper triangles) and the four WRF simulations (gray crosses) is shown in $\mathbf{c}$. The red upper triangle represents the ensemble of 7 reanalysis datasets; the red cross represents the average of 4 WRF simulations (a) Reanalysis Ensemble

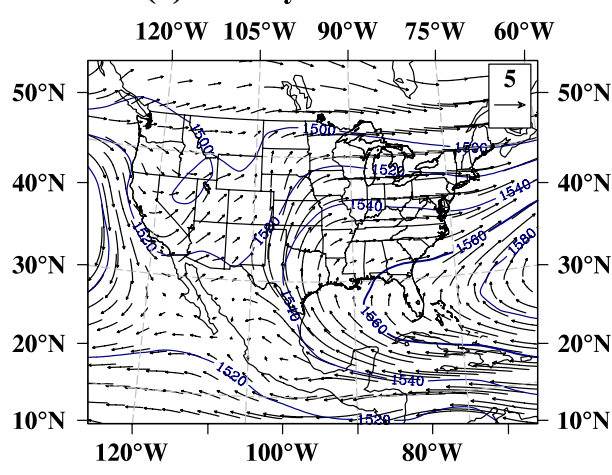

(c) NASH western Ridge

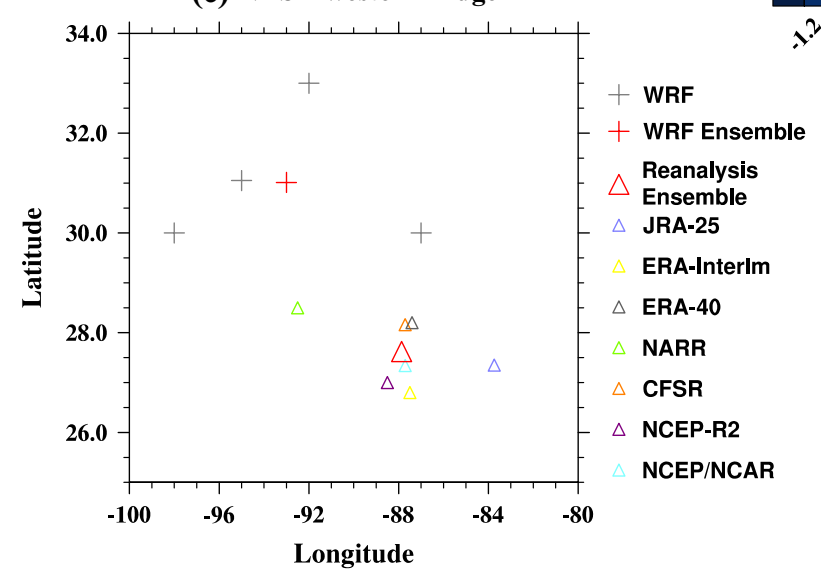

(b) WRF

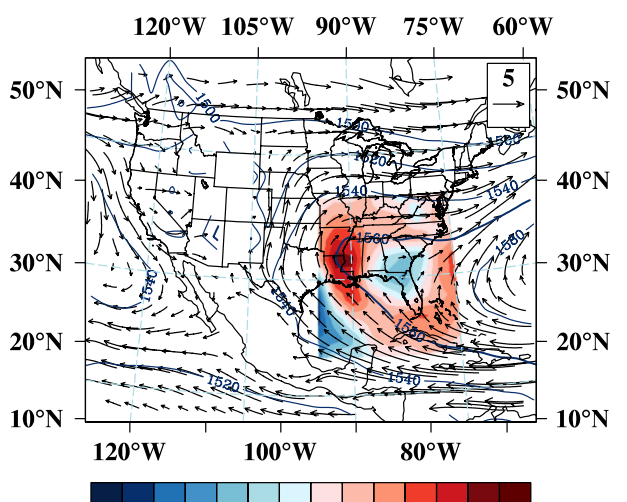

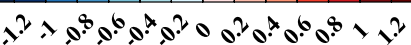

due to thermodynamic (dynamic) FDDA can be attributed to the correction of atmospheric thermodynamic (dynamic) structures. The experiment without FDDA was defined as the control experiment. We ran both thermodynamic and dynamic FDDA with the four different cumulus schemes as in the control experiment.

Figure 7 shows the CONUS JJA precipitation and precipitation bias after applying the dynamic and thermodynamic FDDA. Compared with the control experiment, the dynamic FDDA experiment substantially reduces the bias in SE US summer precipitation. Over the SE US domain, summer precipitation increases to $\sim 5 \mathrm{~mm} \mathrm{day}^{-1}$ (Fig. 7a). The domain-averaged bias is reduced to $-0.3 \mathrm{~mm} \mathrm{day}^{-1}$, indicating that about $80 \%$ of the original dry bias in the control experiment has been corrected (Fig. 7c). Furthermore, the spatial distribution of precipitation, especially the southeast-northwest gradient, is also reasonably simulated in the dynamic FDDA (Fig. 7a). Thus, the dynamic FDDA suggests the importance of atmospheric dynamics in generating satisfactory skill in simulating SE US summer precipitation.

In contrast, the thermodynamic FDDA does not improve the simulation of SE US summer precipitation as significantly as the dynamic FDDA. Specifically, in the thermodynamic FDDA experiment, the SE US dry bias is not meaningfully reduced (Fig. 7b, d). The areal-averaged precipitation bias reaches $-2.0 \mathrm{~mm} \mathrm{day}^{-1}$ in the thermodynamic FDDA experiment, compared to the bias of $-1.3 \mathrm{~mm}$ day $^{-1}$ in the control experiment. In addition, the amount of rainfall decreases over the coastal regions, and the spatial gradient of rainfall further weakens (Fig. 7b). Thus, merely improving atmospheric thermodynamics cannot improve RCM simulations of SE US summer precipitation. The inability of the thermodynamic FDDA to improve the rainfall simulation further indicates that the reduced SE US summer precipitation bias in the dynamic FDDA more likely results from direct dynamic contributions rather than thermally driven circulation.

In summary, the experiments utilizing FDDA collectively suggest that atmospheric dynamics play a direct and predominant role in regulating SE US summer precipitation at seasonal scales. The results from the FDDA experiments are consistent with previous observational results of SE US summer precipitation based on the regional moisture budget (Li et al. 2013a). Over the SE US, large-scale circulation contributes to more than $90 \%$ of the variance in moisture transport that is related to SE US summer precipitation, whereas thermodynamic (temperature and specific humidity) contribution accounts for less than $10 \%$ (Li et al. 2013a). The observed characteristics of SE US 

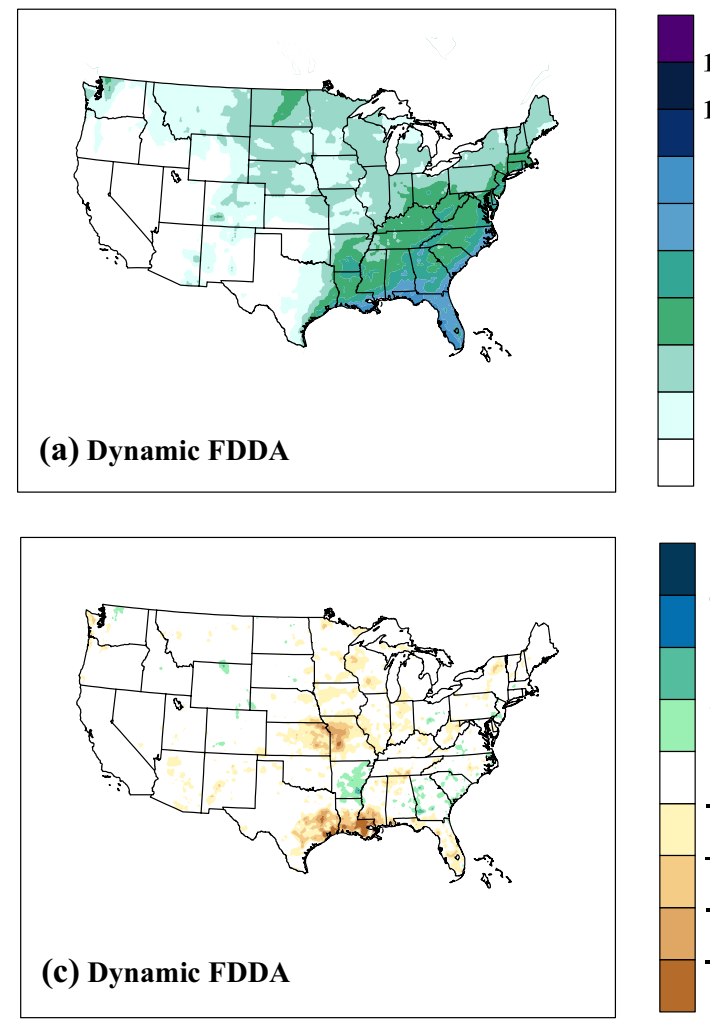
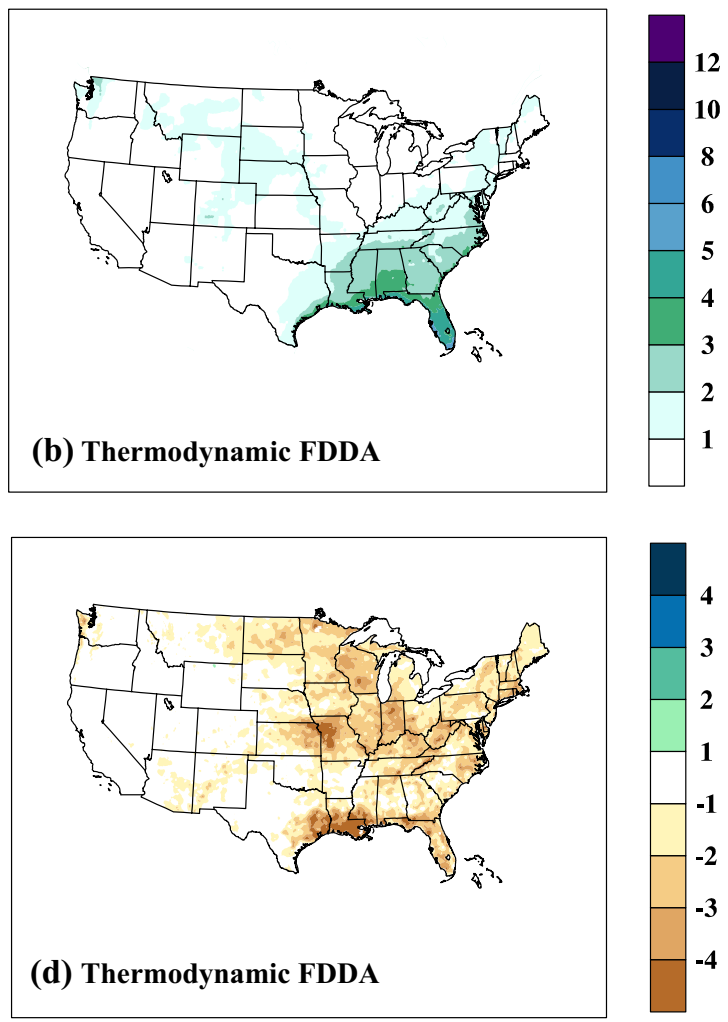

Fig. 72001 JJA summer precipitation (shaded, unit: $\mathrm{mm} \mathrm{day}^{-1}$ ) as simulated in the a thermodynamic FDDA, and b dynamic FDDA experiment; and the precipitation bias in $\mathbf{c}$ thermodynamic and $\mathbf{d}$ dynamic FDDA. The results are shown as the average of the four cumulus schemes

hydrological cycle indicate that errors in large-scale circulation could easily translate into summer precipitation bias due to its important role in atmospheric moisture budget (Li et al. 2013a). Thus, the distortion of the NASH western ridge and the associated circulation in the WRF simulations could result in the precipitation bias over the SE US (Figs. 4, 5, 6). This indicates that better representation of large-scale dynamics can improve the performance of RCMs in simulating the climate over the SE US.

\section{Discussion: planetary boundary layer processes over the tropical oceans and their relationship with the NASH western ridge in RCM simulations}

The above analysis identifies the inaccurate simulation of the NASH western ridge as an important factor in causing the RCM bias in simulating SE US summer precipitation. Thus, exploring the processes responsible for the simulations of the NASH in RCMs is central to understanding the physical mechanisms that determine the skill of RCMs in simulating SE US summer precipitation.

Previous studies have shown that the NASH western ridge actively interacts with the tropical circulation over the Gulf of Mexico and the North Atlantic warm pool through tropical-extratropical teleconnection (e.g., Kosaka and Nakamura 2010; Kushnir et al. 2010; Kelly and Mapes 2011; Li et al. 2012a). In addition, previous RCM simulations of US climate suggested that the Gulf of Mexico is an important region that affects rainfall simulations over the SE US (e.g., Liang et al. 2001; Xue et al. 2007). Thus, whether and how simulated tropical circulation introduces the biases to the NASH western ridge was investigated.

Condensational heating over the tropical Atlantic has been identified as the primary forcing on the NASH western ridge and associated circulation (e.g., Kosaka and Nakamura 2010; Ji et al. 2014), mainly through the northeastward-propagating Rossby waves and the resultant tropical-extratropical teleconnection (e.g., Gill 1980; Hoskins and Karoly 1981; Kosaka and Nakamura 2010). Over the Gulf of Mexico, excessive precipitation is usually associated with an anomalous low-pressure system in the tropics, inducing an anomalous high pressure in the subtropics ( $\mathrm{Ji}$ et al. 2014). The anomalous high pressure reinforces the negative vorticity along the NASH western ridge, extending the ridge into the continental US (e.g., Kosaka and Nakamura 2010; Kushnir et al. 2010; Li et al. 2012a; Ji et al. 2014). Thus, the simulations of tropical precipitation and the associated condensational heat release might be 
keys for representing the NASH western ridge in the WRF model.

In the tropics, the generation and development of convective precipitation depends on the moisture and heat exchanges between the ocean surface and the free atmosphere. The planetary boundary layer (PBL) is an important atmospheric layer for such exchanges, and accurate PBL parameterizations in the WRF model are crucial to realistic simulations of convective precipitation. Thus, we tested the influence of different PBL schemes on tropical circulation, the NASH western ridge, and SE US summer precipitation. Four additional PBL schemes were tested, with the other physical parameterization schemes remaining the same as in the control experiment. The four schemes are the asymmetric convective model version 2 (ACM2), Mellor-Yamada Nakanishi and Niino Level 2.5 (MYNN2.5), Bougeault-Lacarrère (BouLac), and University of Washington (UW) schemes.

According to the analysis, the changes in the PBL schemes result in the spread of the simulated precipitation bias over the SE US. Figure 8 shows the probability density function (PDF) of the WRF-simulated summer precipitation bias over the terrestrial SE US domain using different PBL schemes. Among the five PBL schemes tested in this study, the modes ${ }^{2}$ of the YSU and ACM2 PDFs are -1.56 and $-0.7 \mathrm{~mm} \mathrm{day}^{-1}$, respectively (Fig. 8), showing a dry bias over the SE US. Thus, these two schemes are categorized as "dry" schemes. In contrast, the BouLac and UW schemes simulate precipitation bias by about $0.8 \mathrm{~mm} \mathrm{day}^{-1}$ (Fig. 8) and are characterized as "wet" schemes. The mode of MYNN2.5 PDF is close to zero. Thus, the MYNN2.5 is a "normal" scheme, according to the probability behavior of the precipitation bias over the SE US domain (Fig. 8).

Corresponding to the precipitation bias, the NASH western ridge in the "dry" schemes is located $6^{\circ}$ northwest of that in the reanalysis ensemble, presenting a typical NWtype ridge (Figs. 6a, 9a). By contrast, the ridge is located over the tropical oceans in the "wet" scheme simulations, slightly southwest of the observations (Fig. 9c). The correspondence between the NASH western ridge patterns and the SE US summer precipitation bias in the PBL experiments further emphasizes the importance of the NASH western ridge in the skill of RCMs in simulating SE US summer precipitation.

The PBL schemes likely impact the simulations of the NASH western ridge and SE US summer precipitation through the modeled PBL height and lower tropospheric stability over the tropical oceans. Figure 10a shows the different PBL heights between the "wet" and "dry" schemes. Generally, the "wet" schemes produce lower PBL heights

\footnotetext{
2 The mode of a PDF curve is where the maximum density of probability is attained.
}

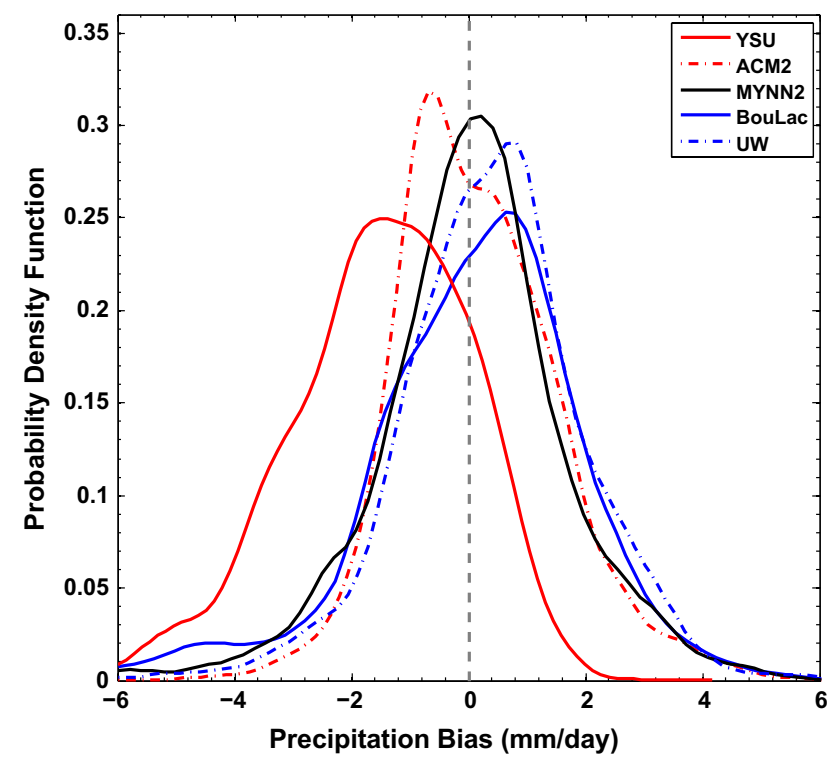

Fig. 8 Probability density function (PDF) curves constructed based on WRF-simulated 2001 summer precipitation bias over the SE US domain using different PBL schemes: YSU (solid red), ACM2 (dashed red), MYNN2 (solid black), BouLac (solid blue), and UW (dashed blue)

over the tropical oceans than the "dry" schemes, with the differences exceeding $100 \mathrm{~m}$ over the Gulf of Mexico (Fig. 10a). The decrease of PBL height in the "wet" schemes weakens turbulent diffusion, which suppresses the heat and moisture fluxes from the ocean surface to the free atmosphere. Simulated atmospheric stability $\left(\frac{\partial \theta_{e}}{\partial z}\right)$ increases in the lower troposphere (Fig. 10b), reducing convective precipitation over the tropical oceans.

The stabilization of the lower troposphere in the Gulf of Mexico and the reduced local convection induces an anomalous high pressure over the ocean. Negative vorticity associated with the anomalous high pressure propagates northeastward in the form of Rossby waves (Hoskins and Karoly 1981), generating positive vorticity and an anomalous low pressure over the SE US (Kosaka and Nakamura 2010; Ji et al. 2014). Such a circulation pattern (Fig. 9c) favors the extension of the NASH western ridge into the Gulf of Mexico, presenting a typical SW-type ridge ( $\mathrm{Li}$ et al. 2012a). The circulation patterns in the "dry" schemes, in which high pressure is formed in the SE US due to excessive tropical convection, are the opposite. Thus, the NASH western ridge moves into the southern US and presents as a typical NW-type ridge.

It is noteworthy that the impact of the PBL schemes on SE US summer precipitation is less likely through their influence on local convection. Our previous study on WRF rainfall simulation showed that SE US local precipitation is only moderately sensitive to the choices of the PBL 

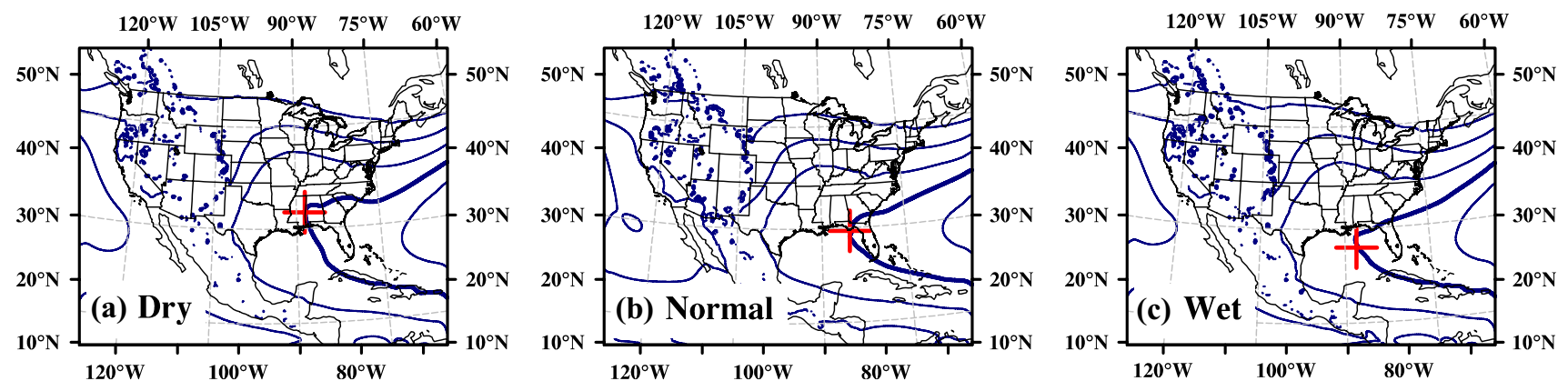

Fig. 92001 JJA $850 \mathrm{hPa}$ geopotential height (contour, unit: gpm) as simulated by a "dry", b "normal", and c "wet" PBL schemes, according to the PDF modes as shown in Fig. 8. The contour inter-

val is 20-gpm, and the bold curves are 1,560-gpm isolines, which are used to represent the NASH western ridge. The red crosses denote the location of the NASH western ridge

Fig. 10 Differences in a PBL height (shaded, unit: $\mathrm{m}$ ), b equivalent potential temperature $\left(\theta_{e} ;\right.$ shaded, unit: $\left.\mathrm{K}\right)$, and c $850 \mathrm{hPa}$ geopotential height (shaded, unit: geopotential meter) between the simulations by "wet" and "dry" PBL schemes
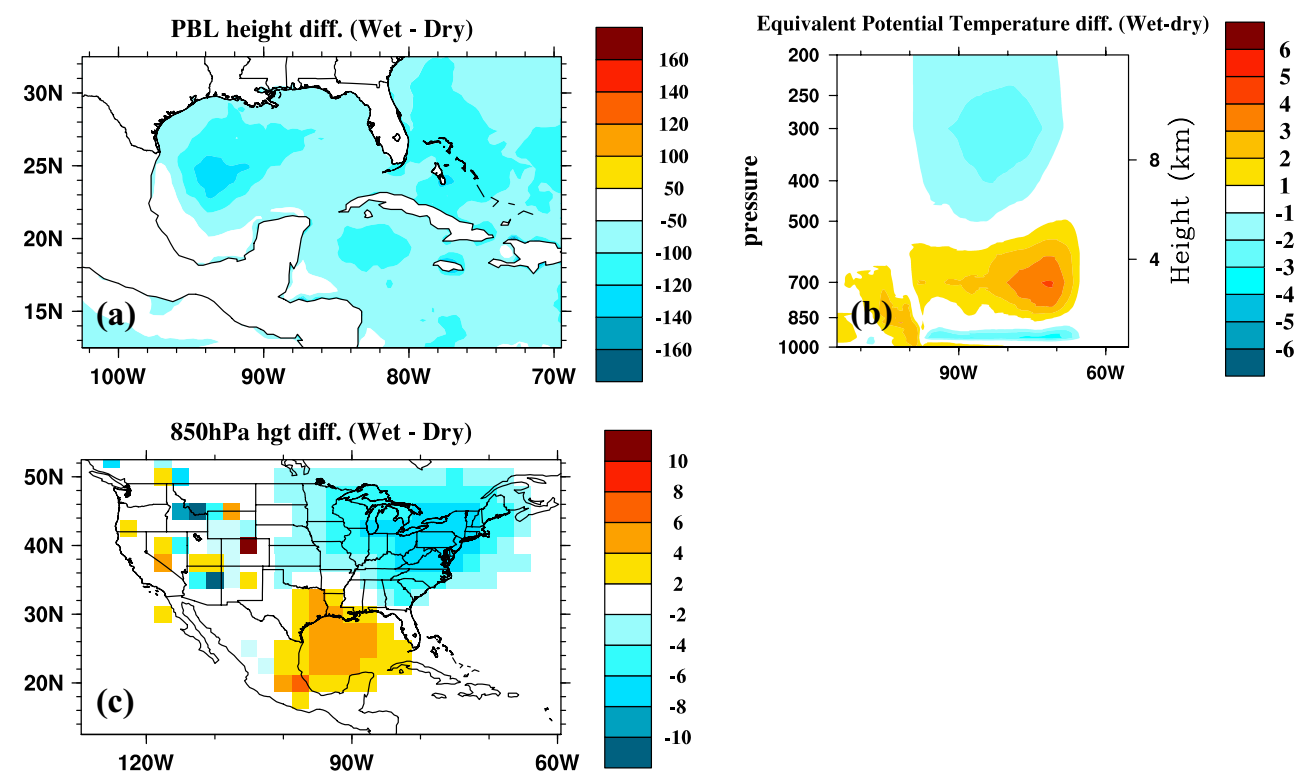

processes might help improve the simulations of SE US summer precipitation by WRF and other RCMs.

\section{Concluding remarks}

This study investigates RCM skill in simulating SE US summer precipitation at a process level. The simulations by RCMs participating in the NARCCAP are analyzed, and WRF simulations are performed for mechanistic study. The analysis of the NARCCAP output shows that large biases and spreads in SE US summer precipitation exist among the state-of-the-art RCMs. Further analysis of the MM5 (wet bias model) and WRF (dry bias model) simulated large-scale circulation links such precipitation bias to the inaccurate simulations of the NASH western ridge.

By performing WRF simulations of the CONUS 2001 summer climate, we find that the modeled precipitation Thus, it is likely that improved simulations of tropical PBL 
biases may not result solely from the choice of cumulus scheme. Instead, the distortion of the large-scale NASH western ridge circulation is likely the cause of the systematic precipitation bias. In the WRF simulations, the NASH western ridge is located erroneously about $7^{\circ}$ northwest of the observation. Such a ridge pattern deflects moisture transport away from the SE US, resulting in the underestimated precipitation $(\mathrm{Li}$ et al. 2011) in the WRF simulations. Thus, it is demonstrated that the NASH western ridge circulation is an important contributor to RCM skill in simulating SE US summer precipitation.

The importance of the NASH western ridge circulation to the simulated SE US precipitation is further supported by two FDDA experiments: dynamic and thermodynamic FDDA. In the dynamic (thermodynamic) FDDA experiment, the WRF-simulated 3-dimensional wind (temperature and specific humidity) is nudged toward NCEP-R2 at each 6-h interval. Correction of circulation dynamics through dynamic FDDA can substantially reduce the bias in SE US summer precipitation, while the correction of thermodynamics cannot significantly improve the rainfall simulations. Thus, the FDDA experiments suggest that an accurate simulation of large-scale dynamics, especially circulation along the NASH western ridge, is needed in order to achieve a reasonable simulation of SE US summer precipitation by RCMs.

Processes responsible for the representation of the NASH circulation in the WRF are further investigated. Results suggest that the simulated PBL processes over the Gulf of Mexico might contribute to the biases in the WRFsimulated NASH western ridge circulation and SE US summer precipitation. Among the five PBL schemes tested in this study, the schemes simulating lower (higher) PBL height over the Gulf of Mexico tend to simulate a more southwestward (northwestward)-located NASH western ridge, and thus wet (dry) biases in SE US summer precipitation. Furthermore, based on our modeling results, the influence of the tropical PBL height on the NASH western ridge circulation results from the changes in lower tropospheric stability, a critical factor for the generation and development of convections. With the changes in convection over the Gulf of Mexico, a different tropical-extratropical teleconnection pattern in $850 \mathrm{hPa}$ geopotential height is generated, which modulates the NASH western ridge circulation and accounts for modeled biases in SE US summer precipitation.

In conclusion, our analysis, primarily based on the WRF simulations of 2001 summer and the analysis of NACCAP models output, suggests that an accurate regional climate simulation of SE US summer precipitation is determined largely by an accurate representation of the NASH western ridge and associated atmospheric circulation in RCMs.
Furthermore, the correction of the NASH circulation dynamics through the FDDA significantly improves the simulation of SE US summer precipitation. Thus, improvement in the simulation of the NASH and the related tropical PBL processes could potentially reduce the uncertainties in RCM-simulated SE US summer precipitation, and thus increase the reliability in the projection of SE US summer climate.

Acknowledgments The authors thank Drs. Fei Chen, Xinzhong Liang, and Liang Guo for insightful discussion; Drs. Lin Zhao, Ying Li, and Mr. Ripley McCoy for technical support; Ms. Laurel Anderton for editorial assistance; and the two anonymous reviewers who provide numerous constructive suggestions to improve the manuscript. This study is supported by the NSF-AGS-1147608, NIH1R21AG044294-01A1, and NSF-EF-1065730.

\section{Appendix: Pattern recognition algorithm and its application to selecting a sample simulation period}

To select a simulation period representative of SE US summer precipitation climatology, an optimization algorithm is designed. The procedure of the algorithm is as follows:

1st: select the years when the areal-averaged SE US summer precipitation anomaly is within one standard deviation of the 1979-2010 sample (Fig. 11a). As shown in Fig. 11a, 22 out of 32 summers fulfill this criterion.

2nd: calculate the pattern correlation coefficient (PCC) and root mean square error (RMSE) between precipitation in each individual summer and the 32-year precipitation climatology (Fig. 11b). The PCC and RMSE are calculated as:

$P C C=\frac{\frac{1}{N-1}\left\{\sum_{i=1}^{N}\left[\left(x_{i}-\bar{x}\right)\left(y_{i}-\bar{y}\right)\right]\right\}}{\left\{\frac{1}{N-1}\left[\sum_{i=1}^{N}\left(x_{i}-\bar{x}\right)^{2}\right]\right\}^{\frac{1}{2}}\left\{\frac{1}{N-1}\left[\sum_{i=1}^{N}\left(y_{i}-\bar{y}\right)^{2}\right]\right\}^{\frac{1}{2}}}$

$R M S E=\left[\frac{1}{N} \sum_{i=1}^{N}\left(x_{i}-y_{i}\right)^{2}\right]^{\frac{1}{2}}$

where $x$ represents precipitation in a specific summer, and $y$ represents the 1979-2010 summer precipitation climatology.

3rd: rank the PCCs (RMSEs) from high to low (low to high). Here, only the years that fulfill the criterion in the first step are considered. The final rank for each summer period is calculated by adding the PCC and RMSE ranks. The years with the highest combined rank are selected as the simulation period.

According to the algorithm, the summer of 2001 is selected, because the precipitation anomaly is within one standard deviation (Fig. 11a) and the combined rank is the 


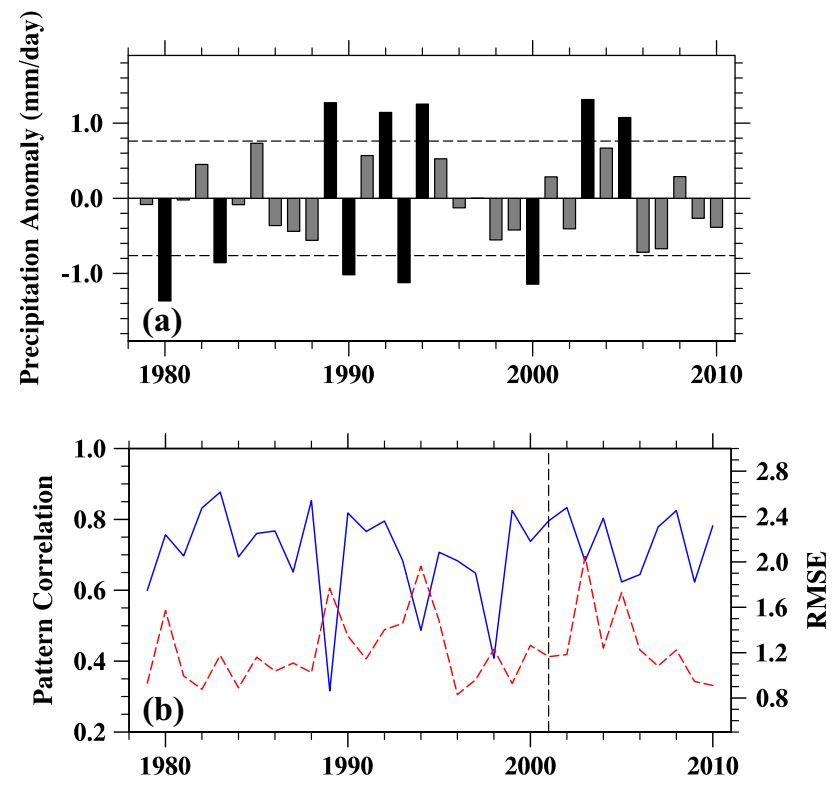

Fig. 11 a Time series of SE US summer precipitation anomalies during 1979-2010; b pattern correlation (solid blue curve, left axis) and root mean square error (RMSE) (dashed red curve, right axis) between each individual year's precipitation and the 1979-2010 precipitation climatology. In a the black (gray) bars represent the years when the precipitation anomaly exceeds (within) one standard deviation of the 32-year precipitation; the dashed lines in a denote one standard deviation of precipitation, and the line in $\mathbf{b}$ denotes the year 2001

highest (Fig. 11b). Furthermore, the results are not sensitive to the choice of simulation period, according to our analysis of the WRF output for NARCCAP.

\section{References}

Anchukaitis KJ, Evans MN, Kaplan A, Vaganov EA, Hughes MK, Grissino-Mayer HD, Cane MA (2006) Forward modeling of regional scale tree-ring patterns in the southeastern United States and the recent influence of summer drought. Geophys Res Lett 33:L04705

Arakawa A (2004) The cumulus parameterization problem: past, present, and future. J Clim 17:2493-2525

Baigorria GA, Jones JW, O'Brien JJ (2007) Understanding rainfall spatial variability in southeast USA at different timescales. Int $\mathrm{J}$ Climatol 27:749-760

Boberg F, Berg P, Thejll P, Gutowski WJ, Christensen JH (2010) Improved confidence in climate change projections of precipitation further evaluated using daily statistics from ENSEMBLES models. Clim Dyn 35:1509-1520

Bowden JH, Nolte CG, Otte TL (2013) Simulating the impact of the large-scale circulation on the 2-m temperature and precipitation climatology. Clim Dynam 40:1903-1920

Bukovsky MS, Karoly DJ (2009) Precipitation simulations using WRF as a nested regional climate model. J Appl Meteor Climatol 48:2152-2159

Carter LM, Jones JW, Berry L, Burkett V, Murley JF, Obeysekera J, Schramm PJ, Wear D (2013) National climate assessment report: Southeast and Caribbean
Castro CL, Pielke RA Sr, Leoncini G (2005) Dynamical downscaling: assessment of value retained and added using the Regional Atmospheric Modeling System (RAMS). J Geophys Res 110:D05108

Chen F, Dudhia J (2001) Coupling an advanced land-surface/hydrology model with the Penn State/NCAR MM5 modeling system. Part I: model description and implementation. Month Weather Rev 129:569-585

Chen M, Pollard D, Barron EJ (2003) Comparison of future climate change over North America simulated by two regional models. J Geophys Res Atmos 108(D12):4348

Davis RE, Hayden BP, Gay DA, Phillips WL, Jones GV (1997) The North Atlantic subtropical anticyclone. J Clim 10:728-744

Dee DP et al (2011) The ERA-interim reanalysis: configuration and performance of the data assimilation system. Quart J R Meteorol Soc 137:553-597

Dudhia J (1989) Numerical study of convection observed during the winter monsoon experiment using a mesoscale two-dimensional model. J Atmos Sci 46:3077-3107

Feser F, Rockel B, Von Storch H, Winterfeldt JRG, Zahn M (2011) Regional climate models add value to global model data. Bull Am Meteorol Soc 92:1181-1192

$\mathrm{Fu} C$ et al (2005) Regional climate model intercomparison project for Asia. Bull Am Meteorol Soc 86:257-266

Gill AE (1980) Some simple solutions for heat-induced tropical circulation. Quart J R Meteorol Soc 106:447-462

Giorgi F, Mearns LO (1999) Introduction to special section: regional climate modeling revisited. J Geophys Res 104:6335-6352

Grell GA, Dévényi D (2002) A generalized approach to parameterizing convection combining ensemble and data assimilation techniques. Geophys Res Lett 29(14):38-41

Hart RE, Evans JL (2001) A climatology of the extratropical transition of Atlantic tropical cyclones. J Clim 14:546-564

Henderson KG, Vega AJ (1996) Regional precipitation variability in the southeastern United States. Phys Geogr 17:93-112

Higgins RW, Shi W, Yarosh E, Joyce R (2000) Improved United States precipitation quality control system and analysis, NCEP/Climate Prediction Center ATLAS No. 7, Camp Springs, MD 20746, USA

Hoskins BJ, Karoly DJ (1981) The steady linear response of a spherical atmosphere to thermal and orographic forcing. J Atmos Sci 38:1179-1196

Hotelling H (1931) The generalization of Student's ratio. Ann Mathem Stat 2:360-378

Janjic ZI (1994) The step-mountain eta coordinate model: further developments of the convection, viscous sublayer and turbulence closure schemes. Month Weather Rev 122:927-945

Janjic ZI (2000) Comments on "development and evaluation of a convection scheme for use in climate models". J Atmos Sci 57:3686

Jankov I, Gallus WA, Segal M, Shaw B, Koch SE (2005) The impact of different WRF model physical parameterizations and their interactions on warm season MCS rainfall. Weather Forecast 20:1048-1060

Ji X, Neelin JD, Lee S-K, Mechoso CR (2014) Interhemispheric teleconnections from tropical heat sources in intermediate and simple models. J Clim 27:684-697

Kain JS (2004) The Kain-Fritsch convective parameterization: an update. J Appl Meteorol 43:170-181

Kalnay et al (1996) The NCEP/NCAR 40-year reanalysis project. Bull Am Meteorol Soc 77:437-470

Kanamitsu M, Ebisuzaki W, Woollen J, Yang S-K, Hnilo JJ, Fiorino M, Potter GL (2002) NCEP-DOE AMIP-II reanalysis (R-2). Bull Am Meteorol Soc 83:1631-1643

Kelly P, Mapes B (2011) Zonal mean wind, the Indian monsoon, and July drying in the western Atlantic subtropics. J Geophys Res Atmos 116:D00Q07

Knight DB, Davis RE (2007) Climatology of tropical cyclone rainfall in the southeastern United States. Phys Geogr 28:126-147 
Konrad CE (1997) Synoptic-scale features associated with warm season heavy rainfall over the interior southeastern United States. Weather Forecast 12:557-571

Kosaka Y, Nakamura H (2010) Mechanisms of meridional teleconnection observed between a summer monsoon system and a subtropical anticyclone. Part II: a global survey. J. Climate 23:5109-5125

Kunkel KE, Easterling DR, Kristovich DAR, Gleason B, Stoecker L, Smith R (2010) Recent increases in U.S. heavy precipitation associated with tropical cyclones. Geophys Res Lett 37:L24706

Kunkel KE, Easterling DR, Kristovich DAR, Gleason B, Stoecker L, Smith R (2012) Meteorological causes of the secular variations in observed extreme precipitation events for the conterminous United States. J Hydrometeor 13:1131-1141

Kushnir Y, Seager R, Ting M, Naik N, Nakamura J (2010) Mechanisms of tropical Atlantic SST influence on North American precipitation variability. J Clim 23:5610-5628

Leung LR, Mearns LO, Giorgi F, Wilby RL (2003) Regional climate research: needs and opportunities. Bull Am Meteorol Soc 84:89-95

Li W, Li L, Fu R, Deng Y, Wang H (2011) Changes to the North Atlantic subtropical high and its role in the intensification of summer rainfall variability in the southeastern United States. J. Climate 24:1499-1506

Li L, Li W, Kushnir Y (2012a) Variation of North Atlantic Subtropical High western ridge and its implication to the southeastern US summer precipitation. Clim Dyn 39:1401-1412

Li W, Li L, Ting M, Liu Y (2012b) Intensification of Northern Hemisphere subtropical highs in a warming climate. Nat Geosci 5:830-834

Li L, Li W, Barros AP (2013a) Atmospheric moisture budget and its regulation of the summer precipitation variability over the Southeastern United States. Clim Dyn 41:613-631

Li L, Li W, Deng Y (2013b) Summer rainfall variability over the southeastern United States in the 21st century as assessed by the CMIP5 models. J Geophys Res 118:340-354

Li L, Li W, Jin J (2014) Improvements in WRF simulation skills of southeastern United States summer rainfall: physical parameterization and horizontal resolution. Clim Dyn 43:2077-2091

Liang X-Z, Kunkel KE, Samel AN (2001) Development of a regional climate model for U.S. Midwest applications. Part I: sensitivity to buffer zone treatment. J. Climate 14:4363-4378

Liang XZ, Pan J, Zhu J, Kunkel KE, Wang JXL, Dai A (2006) Regional climate model downscaling of the U.S. summer climate and future change. J Geophys Res Atmos 111:D10108

Liang X-Z et al (2012) Regional climate-weather research and forecasting model. Bull Am Meteorol Soc 93:1363-1387

Liu Y, Wu G (2004) Progress in the study on the formation of the summertime subtropical anticyclone. Adv Atmos Sci 21:322-342

Lo JCF, Yang ZL, Pielke RA Sr (2008) Assessment of three dynamical climate downscaling methods using the Weather Research and Forecasting (WRF) model. J Geophys Res 113:D09112

Manuel J (2008) Drought in the southeast: lessons for water management. Environ Health Perspect 116:A168-A171

Martinez CJ, Baigorria GA, Jones JW (2009) Use of climate indices to predict corn yields in southeast USA. Int $\mathrm{J}$ Climatol 29:1680-1691

Mearns LO, Giorgi F, McDaniel L, Shields C (2003) Climate scenarios for the southeastern U.S. based on GCM and regional model simulations. Clim Change 60:7-35

Mearns LO, Gutowski WJ, Jones R, Leung L-Y, McGinnis S, Nunes AMB, Qian Y (2009) A regional climate change assessment program for North America. EOS Trans Am Geophys Union 90:311-312

Mearns LO et al (2012) The North American regional climate change assessment program: overview of Phase I results. Bull Am Meteorol Soc 93:1337-1362
Mesinger F et al (2006) North American regional reanalysis. Bull Am Meteorol Soc 87:343-360

Mlawer EJ, Taubman SJ, Brown PD, Iacono MJ, Clough SA (1997) Radiative transfer for inhomogeneous atmosphere: RRTM, a validated correlated-k model for the long-wave. J Geophys Res 102(D14):16663-16682

Noh Y, Cheon WG, Hong SY, Raasch S (2003) Improvement of the K-profile model for the planetary boundary layer based on large eddy simulation data. Bound Layer Meteor 107:421-427

Onogi K et al (2007) The JRA-25 reanalysis. J Meteorol Soc Jpn 85:369-432

Otte TL, Nolte CG, Otte MJ, Bowden JH (2012) Does nudging squelch the extremes in regional climate modeling? J Clim 25:7046-7066

Rauscher SA, Coppola E, Piani C, Giorgi F (2010) Resolution effects on regional climate model simulations of seasonal precipitation over Europe. Clim Dyn 35:685-711

Riha SJ, Wilks DS, Simoens P (1996) Impact of temperature and precipitation variability on crop model predictions. Clim Change 32:293-311

Rummukainen M (2010) State-of-the-art with regional climate models. WIREs Clim Change 1:82-96

Saha $\mathrm{S}$ et al (2010) The NCEP climate forecast system reanalysis. Bull Am Meteorol Soc 91:1015-1057

Seager R, Tzanova A, Nakamura J (2009) Drought in the southeastern United States: causes, variability over the last millennium and the potential for future hydroclimate change. J Clim 22:5021-5045

Skamarock WC, Klemp JB (2008) A time-split nonhydrostatic atmospheric model for weather research and forecasting applications. $\mathrm{J}$ Comput Phys 227:3465-3485

Sobolowski S, Pavelsky T (2012) Evaluation of present and future North American Regional Climate Change Assessment Program (NARCCAP) regional climate simulations over the southeast United States. J Geophys Res 117:D01101

Stauffer DR, Seaman NL (1990) Use of four-dimensional data assimilation in a limited-area mesoscale model. Part I: experiments with synoptic-scale data. Month Weather Rev 118:1250-1277

Thompson G, Field PR, Rasmussen RM, Hall WD (2008) Explicit forecasts of winter precipitation using an improved bulk microphysics scheme. Part II: implementation of a new snow parameterization. Month Weather Rev 136:5095-5115

Uppala SM et al (2005) The ERA-40 re-analysis. Quart J R Meteorol Soc 131:2961-3012

Wang C, Lee S-K, Enfield DB (2008) Climate response to anomalously large and small Atlantic warm pools during the summer. J Clim 21:2437-2450

Wang H, Fu R, Kumar A, Li W (2010) Intensification of summer rainfall variability in the southeastern United States during recent decades. J Hydrometeor 11:1007-1018

Wood AW, Leung LR, Sridhar V, Lettenmaier DP (2004) Hydrologic implications of dynamical and statistical downscaling approaches to downscaling climate model outputs. Clim Change 62:189-216

Wu W, Dickinson RE, Wang H, Liu Y, Shaikha M (2007) Covariabilities of spring soil moisture and summertime United States precipitation in a climate simulation. Int J Climatol 27:429-438

Wuebbles D et al (2014) CMIP5 climate model analyses: climate extremes in the United States. Bu Am Meteorol Soc 95:571-583

Xue Y, Vasic R, Janjic Z, Mesinger F, Mitchell KE (2007) Assessment of dynamic downscaling of the continental U.S. regional climate using the Eta/SSiB regional climate model. J Clim 20:4172-4193

Xue Y, Vasic R, Janjic Z, Liu Y, Chu PC (2012) The impact of spring subsurface soil temperature anomaly in the western U.S. on North American summer precipitation: a case study using regional climate model downscaling. J Geophys Res 117:D11103 
Zhang GJ, McFarlane NA (1995) Sensitivity of climate simulations to the parameterization of cumulus convection in Canadian Climate Center general circulation model. Atmos Ocean 33:407-446
Zhang P, Li G, Fu X, Liu Y, Li L (2014) Clustering of Tibetan Plateau vortices by 10-30-day intraseasonal oscillation. Month Weather Rev 142:290-300 